\title{
Avaliação da Qualidade da Água do Ribeirão dos Müller, Curitiba-PR
}

\author{
Denise Teixeira Bregunce, Elaine Nunes Jordan, Maurício Dziedzic, \\ Leila Teresinha Maranho, Selma Aparecida Cubas \\ Universidade Positivo - UP/PR \\ selmacubas@up.com.br
}

Recebido: 20/05/09 - revisado: 10/08/10 - aceito: 28/07/11

\begin{abstract}
RESUMO
O Ribeirão dos Müller é afluente do Rio Barigui, situado a oeste do município de Curitiba - PR. Nasce em uma densa área populacional, composta de residências e comércios, atravessa toda a extensão do Campus da Universidade Positivo e grande parte da cidade industrial de Curitiba, onde deságua no Rio Barigui. É formado por uma pequena bacia hidrográfica com 10,29 $\mathrm{km}^{2}$ de área. Como muitos rios do município, o Ribeirão dos Müller vem passando por um processo de degradação e ou poluição, principalmente pela falta de infraestrutura de saneamento básico da região. O objetivo do trabalho foi avaliar a qualidade das águas do Ribeirão, no trecho em que corta a Universidade Positivo, e verificar se a situação atual em que se encontra é compatível com a Classe 3, na qual foi enquadrado, segundo a portaria SUREHMA n 92 de 20 de setembro de 1992, artigo $1^{\circ}$, inciso VII. A avaliação da qualidade das águas do Ribeirão dos Müller foi feita por parâmetros físico-químicos e microbiológicos. Foram coletadas 24 amostras, entre fevereiro a agosto de 2007. Dentro do Campus da Universidade Positivo, o Ribeirão dos Müller apresenta um odor desagradável e coloração acinzentada, semelhante ao esgoto doméstico. Os resultados indicaram baixa concentração de Oxigênio Dissolvido (OD), com valores de 1,14 \pm 0,94 mg. $\mathrm{L}^{-1}$, alta concentração de matéria orgânica (DQO), com valores igual a 250,82 $\pm 186,48$ mg. $L^{-1}$, e presença de metais traços como o chumbo $(\mathrm{Pb})$, com valores igual a $1,55 \pm 0,04 \mathrm{mg} . \mathrm{L}^{-1}$. Os resultados também mostraram altas concentrações de coliformes totais (CT), $16 \times 10^{6} \mathrm{NMP} .100 \mathrm{~mL}^{-1}$, coliformes termotolerantes, com $10 \times 10^{6} \mathrm{NMP} .100 \mathrm{~mL}^{-1}$, com presença de Escherichia coli em todas as amostras. A atual situação do Ribeirão dos Müller é crítica, ultrapassa todos os limites estabelecidos pelo CONAMA 357/05 para uma classe 3.
\end{abstract}

Palavras chaves: Rio, qualidade da água, esgoto, águas urbanas poluídas.

\section{INTRODUÇÃOO}

O desenvolvimento ocorrido no Brasil, principalmente nas últimas três décadas, tem produzido impactos significativos ao meio ambiente, causados pelo elevado grau de urbanização, que na maioria das vezes, ocorreu sem um planejamento sobre uso e ocupação do solo e sem um plano de gestão integrado de bacias hidrográficas. Isto acelerou a degradação dos recursos naturais, principalmente hídricos, através da contaminação dos mananciais superficiais e subterrâneo, tornando-os indisponíveis para o uso humano.

A bacia hidrográfica é um cenário para a gestão ambiental e nela podem estar concentradas todas as atividades geradas naturalmente ou por ações antrópicas (Zorzal et al., 2005).
O estudo foi realizado para o Município de Curitiba que é dividido, basicamente, em seis grandes Bacias Hidrográficas: Iguaçu, Atuba, Bacacheri, Belém, Passaúna, Ribeirão dos Padilha e Barigui. A bacia hidrográfica do rio Barigui apresenta forma alongada com área de drenagem igual a 279,11 km², sendo 140,8 km² no Município de Curitiba. Tem como principais afluentes o rio Vila Formosa, rio Passo do França, arroio do Andrada, arroio da Ordem, arroio Pulador, rio Tanguá, rio Uvu, rio Campo Comprido e o Ribeirão dos Muller.

Desde 1992, o Instituto Ambiental do Paraná (IAP) faz o monitoramento da qualidade das águas nas principais bacias hidrográficas do Município de Curitiba e região metropolitana, com a finalidade de informar a população sobre as condições de qualidade dos recursos hídricos, além de servir como suporte para: o planejamento local e regional, a gestão dos recursos hídricos e a avaliação dos programas de saneamento e recuperação ambiental. 
$\mathrm{Na}$ bacia do rio Barigui são cinco pontos de monitoramento, quatro pontos distribuídos ao longo do leito do rio Barigui e um ponto na foz do rio Uvu, afluente da margem direita. Em todos os pontos de monitoramento, de 1992 a 2009, a classificação varia entre poluída e muito poluída (IAP, 2009). Nenhum ponto de monitoramento, porém, está localizado no Ribeirão dos Müller.

Esse ribeirão localiza-se na região oeste da cidade de Curitiba, atravessando os bairros de Campo Comprido e Cidade Industrial. Drena uma área de aproximadamente $10,29 \mathrm{~km}^{2}$ e abrange uma região composta por residências, indústrias, comércio e pelo Campus da Universidade Positivo.

Por se tratar de uma bacia urbana, sofre muitos desequilíbrios ambientais, consequência das ocupações irregulares das margens, da falta de infraestrutura de saneamento básico como: coleta e tratamento de esgoto sanitário, disposição adequada dos resíduos sólidos e um sistema eficiente de drenagem urbana. Além disso, devido ao processo de urbanização, sofre com o desmatamento, confinamento do leito e impermeabilização do solo.

Assim, o objetivo deste trabalho é avaliar a qualidade da água do ribeirão dos Müller, no trecho em que corta a Universidade Positivo, e verificar se a situação atual em que se encontra é compatível com a Classe 3 na qual foi enquadrado, segundo a portaria SUREHMA $\mathrm{n}^{\circ} 92$ de 20 de setembro de 1992, artigo $1^{\circ}$, inciso VII. A classificação 3 , conforme o CONAMA 357/05, refere-se ao abastecimento para consumo humano, após receber tratamento convencional ou avançado, irrigação arbórea, cerealíferas e forrageiras, pesca amadora, recreação secundária e dessendentação de animais.

\section{REVISÃO BIBLIOGRÁFICA}

A população é figura principal no desenvolvimento urbano. No Brasil, $83 \%$ do total da população residem em área urbana, com conseqüente proliferação das áreas de periferia, próximas a mananciais, o que aumenta os problemas de poluição e inundações. Um exemplo é a ocupação irregular das regiões ribeirinhas, que pertencem ao poder público, as quais são invadidas pela população de menor renda, gerando impactos freqüentes (Tucci, 2005). Essas regiões são ambientalmente frágeis, formadas por fundos de vales, encostas e áreas de proteção ambiental (Pereira, 2001).

A urbanização tem como principal impacto o aumento da carga de sedimentos provocada, prin- cipalmente, pela falta de proteção do solo, somado ao lançamento de resíduos sólidos (lixo) no sistema de drenagem, perda da qualidade das águas superficiais e subterrâneas geradas pela lavagem de ruas, transportes de materiais sólidos, e ligações clandestinas de esgotos, ou seja, a disposição de esgotos sem tratamento é a principal fonte de poluição dos recursos hídricos e está diretamente associada à falta de infra-estrutura de saneamento (Tundisi, 2005).

As impurezas da atmosfera ou do solo, carregadas pelas chuvas, lixo jogado em vias públicas, defensivos agrícolas e fertilizantes utilizados na agricultura e desmatamento, no entanto, também são considerados importantes poluentes dos recursos hídricos (Philippi; Martino, 2005).

Segundo o IBGE (2000), no Brasil, 47,8\% dos domicílios não têm coleta de esgoto, $32 \%$ possuem coleta, no entanto o esgoto não é tratado, e somente $20,2 \%$ dos domicílios têm esgoto coletado e tratado. Esse esgoto, tratado ou não, na maioria dos casos, é lançado nos rios, ou seja, segundo a mesma pesquisa, $84,6 \%$ dos esgotos in natura são lançados diretamente nos rios. Em Curitiba, segundo dados da Companhia de Saneamento do Paraná (SANEPAR, 2008), 89,42\% do esgoto coletado recebem tratamento; ao passo que o atendimento de rede de esgoto não ultrapassa $82,07 \%$. Portanto, pode-se concluir que, aproximadamente, $30 \%$ de todo o esgoto gerado em Curitiba é lançado in natura nos rios e afluentes como o Bacacheri, Belém, Padilha, Atuba, Iguaçu e Barigui (do qual o Ribeirão dos Müller é afluente). Esses rios percorrem as áreas mais urbanizadas da cidade de Curitiba e têm a qualidade de suas águas comprometidas não só pelo esgoto sanitário, mas em muitos casos pelo industrial (Zorzal et al., 2005).

Scheffer et al. (2007) fizeram uma caracterização físico-química (denominada pelos autores de parâmetros aquáticos) nos rios Iraí, Belém, Iguaçu e Barigui do município de Curitiba e concluíram que o nível de ocupação e as atividades desenvolvidas na região da bacia têm forte influência nas características do rio. Destacam que o descarte clandestino de esgoto doméstico é a principal fonte de poluição.

O uso e ocupação da bacia hidrográfica apresentam reflexos diretos na qualidade da água e nas populações que vivem próximas a ela, que podem ser mensurados e quantificados pelos indicadores ou parâmetros da qualidade da água (Cunha et al., 2005).

A resolução CONAMA 357 de 2005, Art. 3º, classifica as águas doces, salobras e salinas do Território Nacional segundo a qualidade requerida para os usos preponderantes e o Art. $4^{\circ}$ classifica as águas 
doces em classe Especial, 1, 2, 3 e 4, especificando os possíveis usos.

No Paraná o enquadramento dos cursos de água foi estabelecido através de 16 portarias da antiga Superintendência de Recursos Hídricos e Meio Ambiente do Estado do Paraná (SUREHMA), uma para cada bacia hidrográfica do Estado, que teve como base a antiga portaria do CONAMA $\mathrm{N}^{\circ} .20$ de 1986. Os cursos de água pertencentes à bacia hidrográfica do Iguaçu foram enquadrados, segundo a Portaria SUREHMA $\mathrm{N}^{\circ} 92$ de 20 de setembro de 1992, artigo $1^{\circ}$, como classe 2, estando entre as exceções, através do inciso VII, o Rio Barigui e seus afluentes localizados à jusante do Parque Barigui, como é o caso do Ribeirão dos Müller, objeto deste estudo, que foram enquadrados como classe 3 , pois estão situados em áreas industriais e de grandes centros urbanos.

No entanto, a dificuldade de se enquadrar rios urbanos com grande aporte de poluição tem suscitado ações no sentido do estabelecimento de um enquadramento com metas progressivas pactuado no ambiente dos comitês de gestão de recursos hídricos (Knapik, 2007).

\section{MATERIAL E MÉTODOS}

\section{Área de estudo}

A bacia hidrográfica do Ribeirão dos Muller, afluente da margem direita do Rio Barigui (Fig. 1), localiza-se no Primeiro Planalto Paranaense, entre as coordenadas de latitude $25^{\circ} 13^{\prime} 24^{\prime \prime}$ e $25^{\circ} 38^{\prime} 23^{\prime \prime}$ sul e

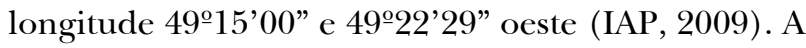
área da bacia apresenta-se com $42,68 \%$ urbanizada, $36,76 \%$ com solo descoberto, $16,55 \%$ com vegetação rasteira, 2,6\% com vegetação densa e apenas 1,4\% da área é coberta por água (Antonietto; Gomes, 2001).

O clima predominante da região, segundo classificação de Köppen, é o Cfb, clima subtropical com verão fresco e úmido e temperaturas variando entre $10^{\circ} \mathrm{C}$ e $22^{\circ} \mathrm{C}$; o inverno é brando com temperaturas entre $-3{ }^{\circ} \mathrm{C}$ e $18{ }^{\circ} \mathrm{C}$. As chuvas são distribuídas por todos os meses, ocorrendo precipitação diária superior a $30 \mathrm{~mm}$. Entretanto, entre março e agosto de 2007, período em que foi monitorada a qualidade da água do ribeirão, o índice pluviométrico médio diário foi de $13,3 \mathrm{~mm}$, com mínima de 0,2 mm e máxima de $54,8 \mathrm{~mm}$ (observado no dia 08 de maio de 2007) (SIMEPAR, 2007).

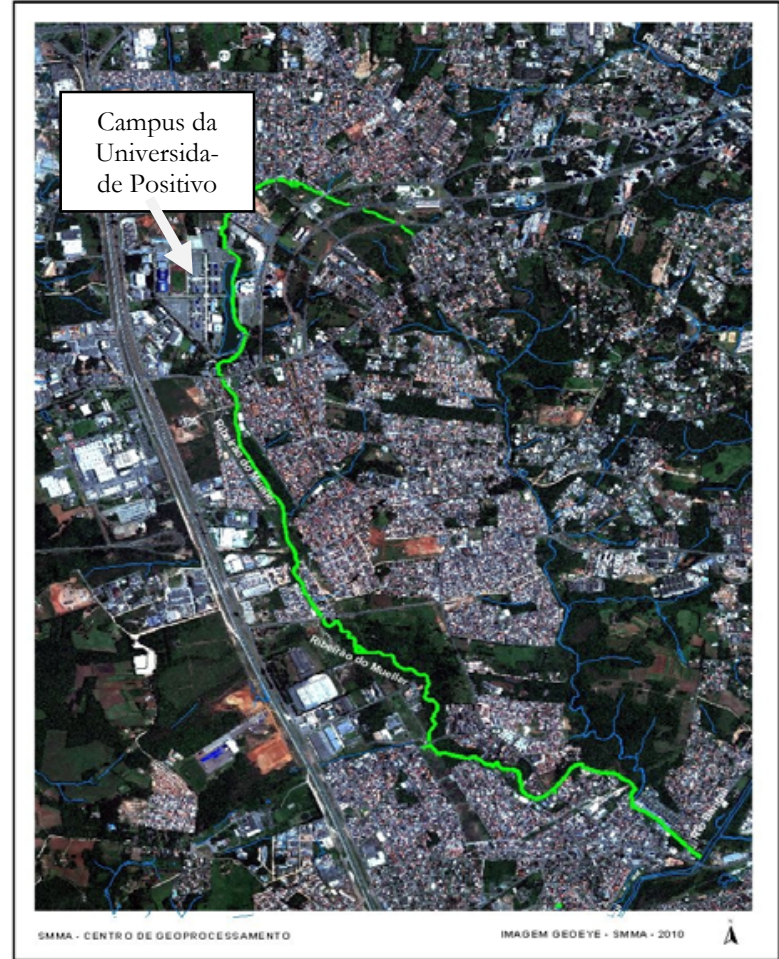

Figura 1 - Foto da área da Bacia Hidrográfica do Ribeirão dos Müller, com destaque ao talvegue principal do Ribeirão (SMMA, 2010)

A vazão média do Ribeirão dos Müller foi estimada por regionalização de vazão, pois não há nenhuma estação fluviométrica em operação no Ribeirão. O método adotado para a estimativa da vazão média de longo período foi proposto por CEHPAR (1999), que utilizou dados de 57 estações fluviométricas com áreas de drenagem menores que $5000 \mathrm{~km}^{2}$, compreendendo a totalidade dos rios pertencentes ao estado do Paraná. A vazão média de longo período estimada foi de $0,185 \mathrm{~m}^{3} \cdot \mathrm{s}^{-1}$, com limites de confiança de $95 \%$ iguais a $0,163 \mathrm{~m}^{3} \cdot \mathrm{s}^{-1} \mathrm{e}$ $0,207 \mathrm{~m}^{3} \cdot \mathrm{s}^{-1}$. A vazão mínima de estiagem de sete dias consecutivos para tempo de recorrência de 10 anos $\left(Q_{7,10}\right)$ foi estimada em $0,039 \mathrm{~m}^{3} \cdot \mathrm{s}^{-1}$, com intervalo de confiança de $95 \%$ entre $0,036 \mathrm{~m}^{3} \cdot \mathrm{s}^{-1}$ e $0,042 \mathrm{~m}^{3} \cdot \mathrm{s}^{-1}$.

\section{Ponto de coleta}

A avaliação da água do ribeirão foi feita entre fevereiro a agosto de 2007 (incluindo três estações do ano: verão, outono e inverno). Foram coletadas 24 amostras e realizadas análises físicoquímicas e biológicas. Todas as coletas de amostras foram realizadas no mesmo ponto (coordenadas 25²6’31” S e 49-21'26” W), em local de remanso, 
próximo ao Biotério da Universidade Positivo (Fig. 2).

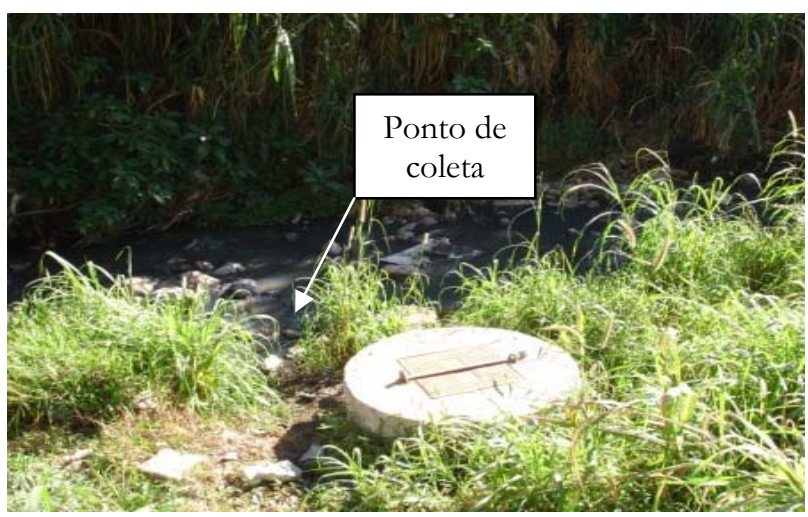

Figura 2 - Foto do local de coleta de amostra - Ribeirão dos Müller, Campus da Universidade Positivo.

\section{Parâmetros}

Os parâmetros físico-químicos e microbiológicos seguiram as rotinas descritas no Standard Methods for the Examination of Water and Watewater (APHA, 2000), As análises de: Temperatura, Cor, Turbidez, pH e Oxigênio Dissolvido (OD), foram feitas in loco (eletrométrico); Sólidos totais (ST), Sólidos Totais Voláteis (STV), Sólidos Totais Fixos (STF), Sólidos Suspensos Totais (SST), Sólidos Suspensos Voláteis (SSV), Sólidos Suspensos Fixos (SSF), através do método gravimétrico; Nitrogênio Amoniacal $\left(\mathrm{NH}_{4}\right)$ pelo método de microKjeldahl; Demanda Química de Oxigênio (DQO), por refluxo fechado; Fósforo Total (P), por ácido Ascórbico; Coliformes Totais (CT), Coliformes Termotolerantes ou Fecais (CF) e Escherichia coli, foi utilizada a técnica dos tubos múltiplos.

Também foram feitas análises de Alcalinidade Total e a Bicarbonato ( $\mathrm{AB}$ ), seguindo a metodologia descrita por Ripley et al. (1986) e de Ácidos Voláteis Totais (AVT), de acordo com a metodologia descrita por Dilallo e Albertson (1961).

A verificação da qualidade da água do Ribeirão quanto à presença de elementos-traço foi realizada em única amostragem. A abertura das amostras seguiu os procedimentos descritos pela Companhia de Tecnologia de Saneamento Ambiental (CETESB, 2004). Os elementos analisados foram Chumbo $(\mathrm{Pb})$, Cromo $(\mathrm{Cr})$, Cobre $(\mathrm{Cu})$, Zinco $(\mathrm{Zn})$, Cádmio (Cd) e Níquel (Ni). A leitura das amostras foi por espectrofotômetro de absorção. Todas as análises foram feitas em duplicata.

\section{RESULTADOS E DISCUSSÃO}

Os resultados dos parâmetros analisados indicam um alto grau de poluição do Ribeirão dos Müller, principalmente por esgoto doméstico. Os valores mínimos e máximos e a média aritmética, com seu respectivo desvio padrão, estão apresentados na Tab. 1.

Tabela 1 - Valores mínimos e máximos e a média aritmética, com seu respectivo desvio padrão dos parâmetros físico-químicos monitorados durante o período de avaliação.

\begin{tabular}{|c|c|c|c|}
\hline \multirow[b]{2}{*}{ Parâmetros } & \multicolumn{3}{|c|}{ Valores } \\
\hline & Mín. & Máx. & Méd. e DP \\
\hline Cor $(\mathrm{uC})$ & 10,00 & 55,00 & $26,80 \pm 11,21$ \\
\hline Turbidez (UNT) & 13,69 & 159,00 & $46,64 \pm 34,10$ \\
\hline $\mathrm{T}\left({ }^{\circ} \mathrm{C}\right)$ & 13,30 & 23,10 & $17,20 \pm 2,24$ \\
\hline ST $\left(m g \cdot L^{-1}\right)$ & 100,02 & 1180,04 & $472,20 \pm 324,80$ \\
\hline STV (mg. $\left.\mathrm{L}^{-1}\right)$ & 20,03 & 680,01 & $168,90 \pm 145,4$ \\
\hline STF (mg.L $\left.\mathrm{L}^{-1}\right)$ & 10,10 & 1100,11 & $315,20 \pm 287,4$ \\
\hline SST (mg.L $\left.L^{-1}\right)$ & 60,04 & 200,13 & $105,00 \pm 43,14$ \\
\hline SSV (mg. $\left.\mathrm{L}^{-1}\right)$ & 20,03 & 1400,17 & $56,67 \pm 39,22$ \\
\hline $\mathrm{SSF}\left(\mathrm{mg} \cdot \mathrm{L}^{-1}\right)$ & 10,07 & 140,03 & $48,33 \pm 34,93$ \\
\hline SDT (mg. $\left.\mathrm{L}^{-1}\right)$ & 20,01 & $1.120,13$ & $329,36 \pm 351,22$ \\
\hline OD (mg. $\left.\mathrm{L}^{-1}\right)$ & 0,46 & 3,95 & $1,14 \pm 0,94$ \\
\hline $\mathrm{DQO}\left(\mathrm{mg} \cdot \mathrm{L}^{-1}\right)$ & 51,00 & 676,00 & $250,82 \pm 186,48$ \\
\hline $\mathrm{pH}$ & 6,70 & 7,80 & $7,30 \pm 0,24$ \\
\hline $\mathrm{AB}\left(\mathrm{mgCaCO}_{3} \cdot \mathrm{L}^{-1}\right)$ & 19,10 & 48,30 & $35,20 \pm 9,12$ \\
\hline AVT (mgAcH.L $\left.L^{-1}\right)$ & 18,10 & 99,03 & $37,90 \pm 19,50$ \\
\hline $\mathrm{N}\left(\mathrm{mgNH}_{4} \cdot \mathrm{L}^{-1}\right)$ & 7,20 & 19,80 & $15,40 \pm 3,560$ \\
\hline $\mathrm{P}\left(\mathrm{mgPO}_{4} \cdot \mathrm{L}^{-1}\right)$ & 1,40 & 5,80 & $3,93 \pm 1,43$ \\
\hline
\end{tabular}

Os resultados mostraram valores entre $10 \mathrm{e}$ $50 \mathrm{uC}$, no entanto, os resultados obtidos nas análises de cor não foram tão elevados quanto os obtidos por Covatti e Queiroz (2007), em alguns trechos do rio Cascavel, sub bacia do rio Cascavel no baixo rio Iguaçu - PR, que foram entre 50 e 220 uC, atribuídos aos impactos causados por ações antrópicas. von Sperling et al. (2007), citam que a cor encontrada em rios impactados por esgotos domésticos geralmente está entre 35 e 200 uC.

Nas observações visuais, as águas do ribeirão têm uma coloração acinzentada, com alguns pontos, às margens, com coloração negra (Fig. 3). A coloração acinzentada, com proximidade à negra, é o resultado das fases de decomposição e concentração da matéria orgânica (Mota, 2006). 


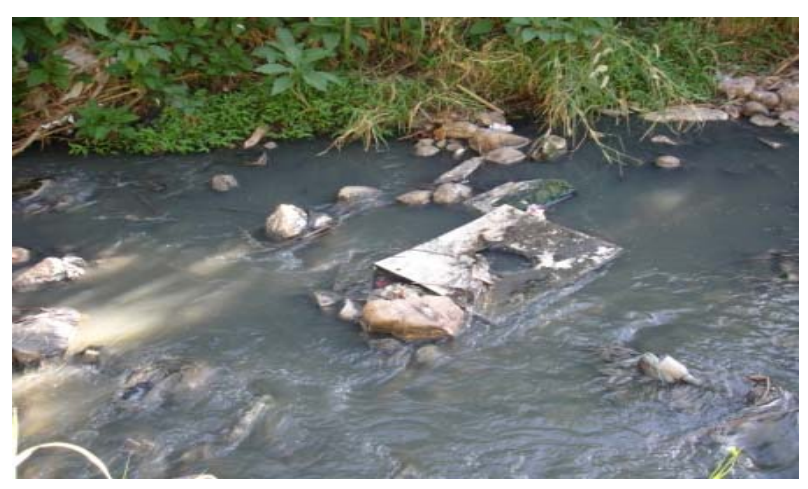

Figura 3 - Foto do ribeirão dos Müller dentro do Campus da Universidade Positivo.

A turbidez, que causa interferência na dispersão da luz na água, e pode ser proveniente de altas concentrações de sólidos em suspensão, compostos químicos dissolvidos, partículas suspensas como silte, argila e matéria orgânica (Nuvolari, 2003; Mota, 2006; Togoro e Marques, 2007), variou de 13,7 a 159,0 UNT. Os altos valores de turbidez, segundo Bernardes e Soares (2005), indicam esgoto fresco e isto foi observado, em visita às margens do ribeirão, onde se verificou lançamentos de dejetos in natura através de tubulações de esgotos.

Em relação aos sólidos presentes, as concentrações de sólidos totais fixos (STF) predominam, em várias amostras, em relação aos sólidos totais voláteis (STV) (Fig. 4), pois esta é uma condição natural das águas dos rios. Entretanto, a situação inversa está relacionada à incidência de matéria orgânica, o que pode ser observado entre o $60^{\circ}$ e o $80^{\circ}$ dia do período de avaliação.

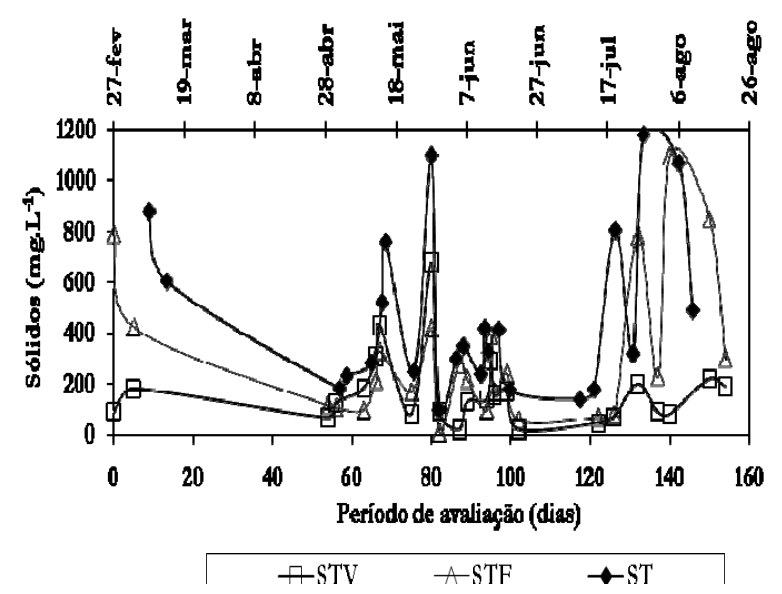

Figura 4 - Concentrações de ST, STV e STF (mg.L $\left.\mathrm{L}^{-1}\right)$ observadas nas águas do ribeirão dos Müller durante o período de avaliação.
Machado et al. (2007) avaliaram a qualidade da água do Ribeirão Piambu - MG, antes e após o lançamento de água residuária doméstica e de laticínio, e observaram que antes do lançamento as concentrações de sólidos totais fixos predominaram em relação aos sólidos totais voláteis e, após o lançamento, os sólidos totais voláteis apresentaram elevadas concentrações em relação aos sólidos fixos. Os autores atribuíram este fato ao aporte de matéria orgânica. Para a concentração de sólidos em suspensão presente nas águas do Ribeirão dos Müller, os valores encontrados indicaram predominância dos sólidos voláteis em relação aos sólidos fixos.

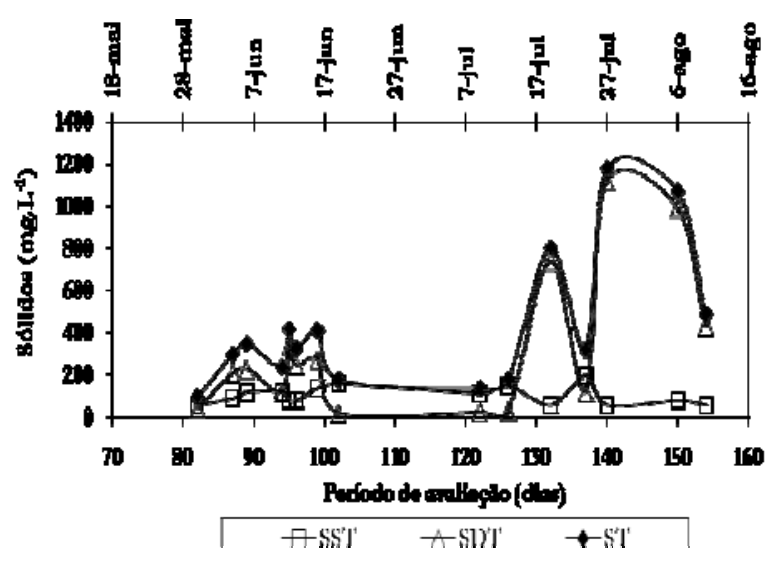

Figura 5 - Concentração de SST, SDT e ST (mg.L $\left.{ }^{-1}\right)$ obtida nas águas do ribeirão dos Müller durante o período de avaliação.

O CONAMA 357/05 cita como parâmetro de monitoramento a concentração de sólidos dissolvidos totais. Para um rio classe 3 a máxima concentração não deve ultrapassar $500 \mathrm{mg} . \mathrm{L}^{-1}$. No Ribeirão dos Müller a média obtida para sólidos dissolvidos totais foi de 329,36 $\pm 351,22 \mathrm{mg} \cdot \mathrm{L}^{-1}$. O grande desvio padrão está associado aos picos de sólidos dissolvidos observados nos dias 19 de julho (dia 130 do período de avaliação), 27 de julho (dia 140 do período de avaliação) e 6 de agosto (dia 150 do período de avaliação), que foram iguais a $744 \mathrm{mg} \cdot \mathrm{L}^{-1}, 1.120$ mg. $\mathrm{L}^{-1}$ e $990 \mathrm{mg} . \mathrm{L}^{-1}$, respectivamente, ultrapassando o limite estabelecido pela legislação (Fig. 5).

A matéria orgânica presente nas águas do Ribeirão dos Müller foi determinada indiretamente pelo método da DQO, com valores médios de 250,82 $\pm 186,48$ mg. $\mathrm{L}^{-1}$, muito semelhantes aos valores típicos de concentração de matéria orgânica encontrada em esgotos domésticos, que variam entre 300 e $500 \mathrm{mg} . \mathrm{L}^{-1}$, aproximadamente (von Sper- 
ling, 2005). Os valores encontrados para matéria orgânica (em DQO) durante o período de avaliação estão apresentados na Fig. 6.

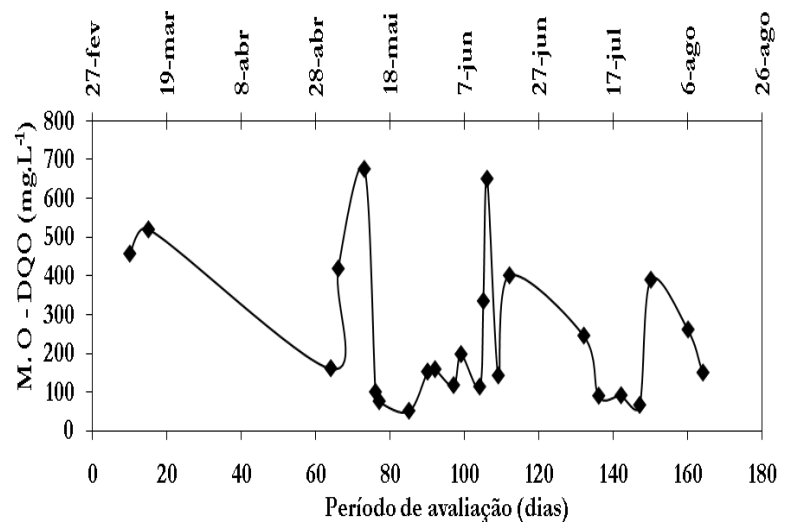

Figura 6 - Concentração de matéria orgânica em DQO (mg.L $\left.{ }^{-1}\right)$ medida nas águas do ribeirão dos Müller durante o período de avaliação.

A alcalinidade a bicarbonato indica a capacidade de tamponamento. No Ribeirão dos Müller, a média obtida para alcalinidade total foi de $61,3 \pm$ $11,3 \mathrm{mgCaCO}_{3} \cdot \mathrm{L}^{-1} \mathrm{e}$ a alcalinidade a bicarbonato foi de $35,2 \pm 9,12 \mathrm{mgCaCO}_{3} \cdot \mathrm{L}^{-1}$. Valores de alcalinidade total também foram medidos por Scheffer et al. (2007) nos rios Iraí, Belém e Iguaçu, com valores médios de 33,30 $\mathrm{mgCaCO}_{3} \cdot \mathrm{L}^{-1}$, no Iraí; 116,3 , no Belém; 123,7 no Iguaçu e $133,0 \mathrm{mgCaCO}_{3} \cdot \mathrm{L}^{-1}$, no Barigui. Nesse estudo, os autores verificaram que o rio Iraí sofria menos impacto de atividades antrópicas e os rios Belém e Iguaçu eram os mais deteriorados por esgotos domésticos, gerando elevados valores de alcalinidade devido à decomposição de nutrientes e substâncias orgânicas, sob condições anaeróbias.

Também foram avaliadas as concentrações de ácidos voláteis totais e os resultados médios obtidos foram iguais a 37,9 $\pm 19,5 \mathrm{mgAcH} . \mathrm{L}^{-1}$. Os ácidos voláteis totais estão presentes nas fases iniciais da degradação anaeróbia da matéria orgânica e, portanto, as concentrações observadas no Ribeirão indicam que a degradação no corpo hídrico está muito próxima da condição de degradação anaeróbia. As concentrações de alcalinidade total, a bicarbonato e ácidos voláteis totais estão apresentadas na Fig. 7.

Esta condição foi comprovada pela avaliação da concentração de OD que apresentou valor médio de $1,14 \pm 0,94 \mathrm{mg} \cdot \mathrm{L}^{-1}$, sendo que, na maioria das amostras os valores ficaram abaixo de $1 \mathrm{mg} . \mathrm{L}^{-1}$. Em todas as amostras a concentração de OD foi inferior ao limite estabelecido pelo CONAMA 357/05, para um rio classe 3, que é, no mínimo, $4 \mathrm{mg} . \mathrm{L}^{-1}$ de OD. Concentrações semelhantes também foram encontradas em alguns rios que cortam o Município de Curitiba como: rio Belém, com concentrações de 1,1 $\mathrm{mg} . \mathrm{L}^{-1}$; rio Iguaçu, com concentrações de $0,2 \mathrm{mg} . \mathrm{L}^{-1}$ e rio Barigui (do qual o Ribeirão dos Müller é afluente), com concentrações de 1,2 mg.L $\mathrm{L}^{-1}$ (Scheffer et al., 2007).

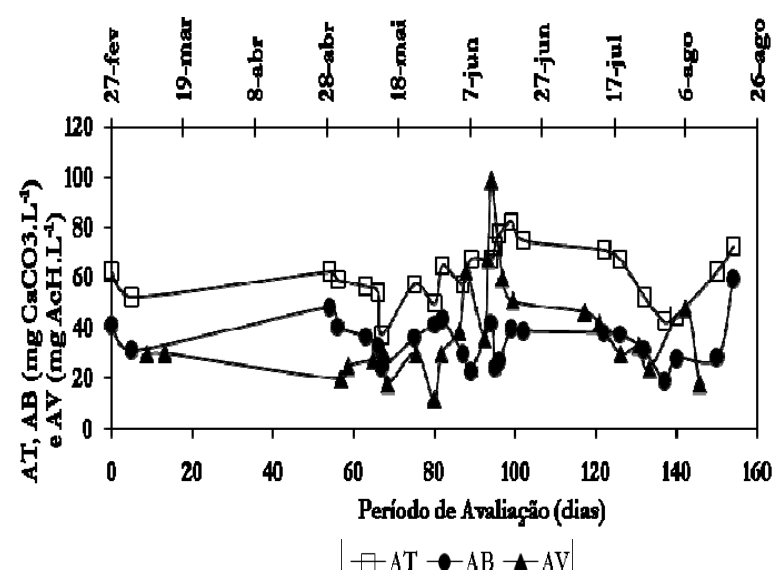

Figura 7 - Concentrações de alcalinidade total, alcalinidade a bicarbonato e ácidos voláteis totais medidas nas águas do Ribeirão dos Müller durante o período de avaliação.

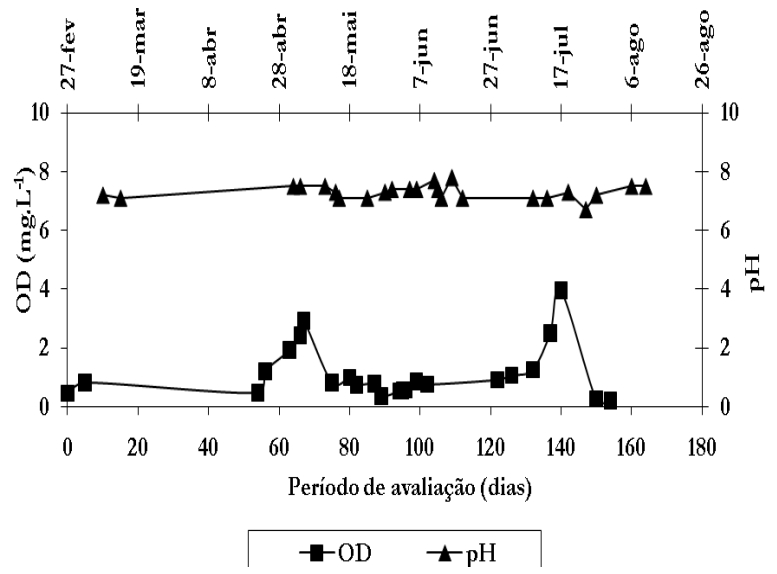

Figura 8 - Concentração de OD $\left(\mathrm{mg}\right.$. $\left.\mathrm{L}^{-1}\right)$ e valores de $\mathrm{pH}$ observados na águas do Ribeirão dos Müller durante o período de avaliação.

Quanto ao $\mathrm{pH}$, as águas do Ribeirão apresentaram pH básico, próximo do neutro, com média em 7,30 $\pm 0,24$, o que, segundo Scheffer et al. 
(2007), é típico da região, pois nos levantamentos feitos nos rios Iraí, Belém, Iguaçu e Barigui, o pH encontrado foi de 6,$5 ; 7,4 ; 7,0$ e 7,6, respectivamente. A Fig. 8 apresenta os valores de OD e pH encontrados nas águas do Ribeirão dos Müller.

Os níveis de nitrogênio e fósforo também indicam o grau de poluição de um corpo hídrico e, dependendo da concentração, podem levar o corpo de água ao estado de eutrofização. Além disso, a forma predominante do nitrogênio pode fornecer indicações sobre o estágio de poluição. $\mathrm{O}$ nitrogênio amoniacal, quando presente, pode ter como origem as seguintes condições: esgoto bruto, poluição recente, estágio intermediário da poluição (von Sperling, 2005).

A média de nitrogênio amoniacal observada no Ribeirão dos Müller foi de $15,4 \pm 3,56 \mathrm{mgNH}_{4} \cdot \mathrm{L}^{-1}$, superior ao limite estabelecido pela resolução CONAMA 357/05, para um rio classe 3, que é de 13,3 $\mathrm{mgNH}_{4} \cdot \mathrm{L}^{-1}$, em ambiente lótico e com $\mathrm{pH}$ menor ou igual a 7,5. Em relação à concentração de fósforo, a resolução CONAMA 357/2005 estabelece que para um rio Classe 3, a concentração de fósforo total não deve ultrapassar 0,15 mgP.L. ${ }^{-1}$. No Ribeirão dos Müller, mesmo a menor concentração encontrada que foi igual a 1,4 mgP. $\mathrm{L}^{-1}$ foi superior ao limite estabelecido pela legislação. Segundo Campos e Jardim (2003), fatores ambientais naturais ou antrópicos podem influenciar na concentração de fósforo presente nas águas, como é o caso do Ribeirão dos Müller.

Quanto às características biológicas, foram realizadas análises de coliformes totais, termotolerantes e verificada a presença de Escherichia coli. Para coliformes totais foi verificado um valor mínimo de $5 \times 10^{6}$ NMP. $100 \mathrm{~mL}^{-1}$ e máximo de $16 \times 10^{6}$ NMP. $100 \mathrm{~mL}^{-1}$, e para os coliformes termotolerantes o mínimo obtido foi de $2,2 \times 10^{6} \mathrm{NMP} .100 \mathrm{~mL}^{-1} \mathrm{e}$ máximo de $16 \times 10^{6} \mathrm{NMP} .100 \mathrm{~mL}^{-1}$.

A resolução CONAMA 357/05 cita que os coliformes termotolerantes estão presentes em fezes humanas, animais homeotérmicos, em solos, plantas ou outras matrizes ambientais que apresentem contaminação por material fecal. Os resultados obtidos na maioria das amostras ultrapassaram os limites estabelecidos por essa resolução, a qual determina que, para contato secundário, em um rio classe 3, não pode ser excedido o limite de $2,5 \times 10^{3}$ coliformes termotolerantes por $100 \mathrm{~mL}$, em $80 \%$ das amostras, em pelo menos 6 amostras, em um período de 1 ano. No Ribeirão dos Müller foram realizadas quatro amostragens e, em todas elas, os valores observados ultrapassaram o limite estabelecido pela legislação. Em todas as amostras coletadas foi obser- vada a presença de E. coli. Segundo o CONAMA 357/05, a única espécie do grupo coliforme termotolerantes, cujo habitat exclusivo é o intestino humano e de animais homeotérmicos é a E. coli.

Os elementos traço, também conhecidos como metais pesados, metais-traço ou micronutrientes, foram analisados em uma única amostra, apenas para constatação de presença. Foi detectado valor médio de chumbo igual a 1,55 $\pm 0,04 \mathrm{mg} \cdot \mathrm{L}^{-1}$ e zinco de 0,07 $\pm 0,02 \mathrm{mg} \cdot \mathrm{L}^{-1}$. Os demais elementos analisados estavam abaixo do limite de detecção do equipamento. A resolução CONAMA 357/05, para um rio classe 3 , apresenta o limite de $0,033 \mathrm{mg} \cdot \mathrm{L}^{-1}$ para $\mathrm{Pb}$ e $5 \mathrm{mg} . \mathrm{L}^{-1}$ para o $\mathrm{Zn}$. Assim, o chumbo ultrapassou o limite estabelecido na legislação.

A presença de chumbo na massa líquida de um rio pode ter diferentes origens, a mais comum é o lançamento de resíduos de fabricação de baterias, tintas, pigmentos, inseticidas, ligas, munição de soldas, escapamento de veículos e águas residuárias industriais Kent (2000). Scheffer et al. (2007) também citam que a presença de metais na coluna de água pode ser resultado de um complexo entre espécies reduzidas de enxofre e metais, que só acontece em ambiente anóxico, favorecido pelos constantes lançamentos de resíduos sanitários.

\section{CONCLUSÃO}

Na avaliação do Ribeirão dos Müller pode-se concluir que ocorre um processo de degradação com baixas atividades de autodepuração. O Ribeirão apresenta baixas concentrações de oxigênio dissolvido $\left(1,14 \pm 0,94 \mathrm{mg} \cdot \mathrm{L}^{-1}\right)$ e altas concentrações de matéria orgânica $\left(250,82 \pm 186,48 \mathrm{mg} \cdot \mathrm{L}^{-1}\right)$, provenientes de lançamentos recentes, principalmente de esgotos domésticos, o que foi confirmado pelas altas concentrações de nitrogênio amoniacal, fósforo e de coliformes termotolerantes, alcançando valores de $16 \times 10^{6} \mathrm{NMP} .100 \mathrm{~mL}^{-1}$, com presença de Escherichia coli.

Possivelmente, além do lançamento de esgoto doméstico, o Ribeirão recebe outro tipo de lançamento de água residuária, pois na análise de elementos traço foi encontrado chumbo com concentração de 1,55 $\pm 0,04 \mathrm{mg} \cdot \mathrm{L}^{-1}$, valor superior ao limite estabelecido pela resolução CONAMA $357 / 05$, que é de $0,033 \mathrm{mg} \cdot \mathrm{L}^{-1}$.

Os dados, em relação à qualidade das águas do Ribeirão dos Müller, indicam uma situação preocupante, pois este se apresenta com alto grau de contaminação, decorrente dos resíduos lançados 
diretamente, sem nenhuma forma de tratamento. $\mathrm{O}$ atual enquadramento do Ribeirão não representa a real situação em que se encontra, pois os dados observados durante a avaliação indicam uma situação que nem a classe IV (CONAMA 357/05), que é destinada a navegação e harmonia paisagística, contempla.

\section{REFERÊNCIAS}

ANTONIETTO, C. GOMES, J. C. Implementação de um modelo digital de terreno para a bacia hidrográfica do Ribeirão dos Muller. Programa de iniciação científica. Centro Universitário Positivo. Curitiba/PR (2001).

APHA, AWWA, WPCF. Standard methods for the examination of water and wastewater. 20. ed. Washington D. C. IUSA, American Public Health Association, 2000.

BRASIL. Conselho Nacional do Meio Ambiente (CONAMA). Resolução CONAMA n. 357, de 17 de março de 2005. Classificação dos corpos de água. Diário Oficial da União, Brasília/DF, 18 mar 2005

BRASIL. Instituto Brasileiro de Geografia e Estatística (IBGE), 2000.

CEHPAR. Centro de Hidráulica e Hidrologia Professor Parigot de Souza. Projeto HG - 52 - Aproveitamentos Hidrelétricos de Pequeno Porte. Regionalização de vazões de estiagem, de curvas de permanência e de vazões máximas de pequenas bacias hidrográficas do Estado do Paraná. v. I a IV. Curitiba - PR., 1999.

COVATTI, J. A. C.; QUEIROZ, M. M. F. Análise qualiquantitativa da água do rio Cascavel. In: IV 067. $2424^{\circ}$ Congresso Brasileiro de Engenharia Sanitária e Ambiental (ABES), Belo Horizonte, set.,2007.

CUNHA, A. C.; CUNHA, H. F. A.; SOUZA, J. A.; NAZARÉ, A. L. Monitoramento de Águas Superficiais em Rios Estuarinos do Estado do Amapá sob Poluição Microbiológica. Bol. Mus. Para. Emílio Goeldi, sér. Ciências Naturais, Pará, v. 1, n. 1, p. 191-199, jan-abr. 2005.

DILALLO, R.; ALBERTSON, O. E. Volatile acids by direct titration. Jornal WPCF. v. 33, n.4, abr.,1961. p. 357365.

ESTADO DO PARANÁ. Instituto Ambiental do Paraná - IAP. Monitoramento da qualidade das águas dos rios da Bacia do Alto Iguaçú, na Região Metropolitana de Curitiba, no período de 2005 a 2009. Curitiba, 2009. P.114. Disponível em: http://www.iap.pr.gov.br/ arquivos/File/boletins/RELATORIO_AGUA/relatóriorios 2005_2009.pdf. Acesso em março, 2010.

ESTADO DO PARANÁ. Sistema Meteorológico do Paraná (SIMEPAR). Dados de precipitação do período entre 1996 e 2007. Informação e- mail. Curitiba/PR, 2008.
ESTADO DO PARANÁ. Superintendência dos Recursos Hídricos e Meio Ambiente (SUREHMA). Portaria No 92 de 20 de Maio de 1992.

ESTADO DE SÃO PAULO. Companhia de Tecnologia de Saneamento Ambiental (CETESB), SP, 2004.

KENT, D. M. Applied wetlands science and technology. 2000, 41-276p.

KNAPIK, H. G. et al. Avaliação da qualidade da água baseado em metodologia de hierarquização de cargos com vistas ao enquadramento com metas progressivas: Estudo de caso da Bacia do Alto Iguaçú. XVII. Simpósio Brasileiro de Recursos Hídricos (ABRH), São Paulo, 2007.

MACHADO, L. P.; GARÇÃO, H. F., FONTANA, G. H.; OLIVEIRA, M. D. Avaliação da qualidade da água da zona estuarina do Rio dos Magos. In: IV $00524^{\circ}$ Congresso Brasileiro de Engenharia Sanitária e Ambiental (ABES), Belo Horizonte, set./2007.

MOTA, S. Introdução a engenharia ambiental. 4. ed. ABES. 2006. 388p.

NUVOLARI, A.; TELLES, D. D.; RIBEIRO, J. T.; MIYASHITA, N. J.; RODRIGUES, R. B.; ARAÚJO, R. Esgoto sanitário, coleta, transporte, tratamento e resíduo agrícola. (Coord.) Ariovaldo Nuvolari. DATEC-SP/CEETPS. s/d. 2003. 503p.

PEREIRA, G. A natureza (dos) nos fatos urbanos: produção do espaço e degradação ambiental. In: SANTOS, M. R. A. (coord.). Desenvolvimento e meio ambiente: cidade e ambiente urbano. Curitiba: UFPR, 2001, v. 3. p. 40

PHILIPPI JR, A.; MARTINS, G. Águas de abastecimento. In: PHILIPPI JR, A. (ed.). Saneamento, saúde e ambiente: fundamentos para um desenvolvimento sustentável. Barueri/SP: Manole, 2005, Coleção ambiental, 2.118,124-125p.

RIPLEY, L. E.; BOYLE, W. C. \& CONVERSE, J. C. (1986) Improved alkalimetric monitoring for anarobic digestion of righ-strenght wastes. J. WPCF, 58, 5. p. 406411.

SCHEFFER, E. W.; SODRÉ, E. F.; GRASSI, M. T. Fatores que governam a especiação do cobre em ambientes aquáticos urbanos: evidências da contribuição de sulfetos solúveis. Revista Química Nova, v. 30, n. 2, 332-338. 2007.

TOGORO, E. S.; MARQUES. M. Qualidade da água e integridade biótica: estudo de caso num trecho fluminense do Rio Paraíba. In: $24^{\circ}$ Congresso Brasileiro de Engenharia Sanitária e Ambiental. (ABES), Belo Horizonte, 2007.

TUCCI, C. E. M. Águas urbanas: Interfaces no gerenciamento. In: PHILIPPI JR, A. (Ed). Saneamento, saúde e ambiente: fundamentos para um desenvolvimento sustentável. Barueri/SP: Manole, 2005, Coleção ambiental, 2. 6; 296; 399, 402, 408p. 
TUNDISI, J. G. Seminários Temáticos para 3a. Conferência Nacional de Ciência e inovação. Parcerias estratégicas, n.20 (pt. 2) Brasília/DF. Jun./2005. 727p. Disponível em <http://www.cgee.org.br/arquivos/p_20_ 2.pdf> Acesso em 12 fev 2008.

VON SPERLING, M. Princípios do Tratamento Biológico de Águas Residuárias. Introdução a qualidade das águas e ao tratamento de esgotos. Departamento de Engenharia Sanitária e Ambiental (DESA) Universidade Federal de Minas Gerais. v. 1, ed. 3, 2005.452p.

VON SPERLING, E.; CASTRO, S. V. Efeitos de metais pesados presentes na água sobre a estrutura das comunidades bentônicas do Alto do Rio das Velhas-MG. In: IV 005. 24 Congresso Brasileiro de Engenharia Sanitária e Ambiental (ABES), Belo Horizonte, set./2007. Belo Horizonte, 2007.

ZORZAL, F. M. B ELIAS, J. L., ELIAS, J. V. V.; JACHIC. J.; MEDINA, A. S. Caracterização da bacia hidrográfica do rio Barigui. Curitiba/PR. In: VI 026. 23․ Congresso Brasileiro de Engenharia Sanitária e Ambiental, Set./2005, Campo Grande/MS.

\section{Evaluation of Water Quality in Ribeirao dos Muller River}

\section{ABSTRACT}

The river called Ribeirão dos Müller is a Barigui River tributary. It is located west of Curitiba, the capital of Paraná, Brazil. Its source is in a highly populated area, with houses and businesses, and it flows through the entire campus of Universidade Positivo and much of the industrial city of Curitiba, where it discharges into Barigui River. It consists of a small $10.29 \mathrm{~km}^{2}$.catchment. As in many rivers in the county, Ribeirão dos Müller has been exposed to degradation due to pollution caused by lack of basic sanitation in the region. This study aimed to evaluate the water quality of the river, in the section where it flows through the campus, and to find out whether its current situation is in accordance with Class 3, its classification according to the SUREHMA Administrative Ruling $N^{0} 92$ of September 20, 1992, article 1, section VII. The water quality assessment of the Ribeirão dos Müller was carried out using physico-chemical and microbiological parameters. Twenty-four samples were collected between February and August 2007. In the Campus, the river has an unpleasant odor and is grayish, similar to domestic wastewater. The results showed a low concentration of dissolved oxygen $(D O)$, with values of $1.14 \pm 0.94 \mathrm{mg} . \mathrm{L}^{-1}$, high concentrations of organic matter (COD)( $250.82 \pm$ $\left.186.48 \mathrm{mg} \cdot \mathrm{L}^{-1}\right)$, and the presence of trace metals such as lead $(\mathrm{Pb})$, with values equal to $1.55 \pm 0.04 \mathrm{mg} \mathrm{L^{-1 }}$. The results also showed high concentrations of total coliforms (TC), $16 \times 10^{6}$ MPN. $100 \mathrm{~mL}^{-1}$, fecal coliforms, $10 \times 106$ MPN. $100 \mathrm{~mL}^{-1}$, with Escherichia coli in all samples. The current situation of Ribeirão dos Müller is critical, and surpasses all limits established by CONAMA 357/05 for Class 3.

Keywords: river, water quality, wastewater; polluted urban water. 